\title{
Immunotherapy for Chronic Hepatitis B Virus Infection
}

\author{
Antonio Bertoletti ${ }^{1,2}$ and Nina Le Bert ${ }^{1,2}$ \\ ${ }^{1}$ Emerging Infectious Diseases Program, Duke-NUS Medical School and ${ }^{2}$ Viral Hepatitis Laboratory, Singapore Institute for Clinical Sciences, \\ $A^{*}$ STAR, Singapore
}

While new therapies for chronic hepatitis $\mathrm{C}$ virus infection have delivered remarkable cure rates, curative therapies for chronic hepatitis B virus (HBV) infection remain a distant goal. Although current direct antiviral therapies are very efficient in controlling viral replication and limiting the progression to cirrhosis, these treatments require lifelong administration due to the frequent viral rebound upon treatment cessation, and immune modulation with interferon is only effective in a subgroup of patients. Specific immunotherapies can offer the possibility of eliminating or at least stably maintaining low levels of HBV replication under the control of a functional host antiviral response. Here, we review the development of immune cell therapy for HBV, highlighting the potential antiviral efficiency and potential toxicities in different groups of chronically infected HBV patients. We also discuss the chronic hepatitis $B$ patient populations that best benefit from therapeutic immune interventions. (Gut Liver 2018;12:497-507)

Key Words: Vaccines; Hepatitis B, chronic; Therapeutics; Hepatitis B virus

\section{INTRODUCTION}

In contrast to most communicable diseases, morbidity and mortality rates related to infection with hepatitis B virus (HBV) and hepatitis $\mathrm{C}$ virus (HCV) have increased over the last 20 years. ${ }^{1}$ The two different viruses (HCV is an RNA virus belonging to Flaviviridae, while HBV is a DNA virus of the Hepadnavirus family) are both hepatotropic, noncytopathic, and able to establish persistent infections that cause different degrees of hepatic inflammations (chronic hepatitis) leading to the development of liver cirrhosis and hepatocellular carcinoma (HCC).

However, the therapeutic advances in their treatment have been radically different. New therapies for HCV have delivered remarkable results, with more than 90\% of patients achieving viral clearance with all-oral treatment with directly acting antivirals. ${ }^{2}$ In contrast, therapy options with curative intent for $\mathrm{HBV}$ are still a distant future ${ }^{3}$ and thus new therapies, targeting either steps of HBV replication or the host immune system, are urgently needed.

\section{LIMITATIONS OF CURRENT THERAPIES FOR HBV}

Current treatments for chronic HBV infection (CHB) include pegylated-interferon- $\alpha$ (Peg-IFN $\alpha$ ) and nucleos(t)ide analogues (NAs), but neither are suitably efficient in providing functional cure, ${ }^{4}$ a virological and clinical situation defined by undetectable levels of hepatitis B surface antigen (HBsAg) and HBV DNA in the serum, normality of alanine aminotransferase (ALT) and development of hepatitis B surface antibody (anti-HBs). The term "functional cure" is thus used to define a virological situation in which, like in patients who resolved acute hepatitis B infection, HBV is not fully eliminated and few hepatocytes harbor covalently closed circular DNA (cccDNA) that is maintained under a repressed translational control by innate and adaptive immune mechanisms (NB, for an extended definition of functional cure in $\mathrm{HBV}$ we recommend ${ }^{3}$ ).

Peg-IFN $\alpha$ can achieve sustained off-treatment control, but only in a limited proportion of patients; approximately 10\%. NAs therapy suppresses the production of new virions, reduces HBV DNA to undetectable levels in the serum and leads to a normalization of transaminases. However, loss of HBsAg is rarely achieved. Furthermore, since NAs suppress HBV replication by targeting at the level of DNA synthesis only, they are ineffective in their ability to eradicate the cccDNA, the episomal form of HBV from infected cells. ${ }^{5}$ Treatment with NAs is thus considered lifelong with the potential risk of long-term toxicity, ${ }^{6}$ with limited data on treatment withdrawal, which results in reactivation of $\mathrm{HBV}$ in the majority, ${ }^{5}$ likely due to a defect on

Correspondence to: Antonio Bertoletti

Emerging Infectious Diseases Program, Duke-NUS Medical School, 8 College Road, Singapore 169857

Tel: +65-6601-3574, Fax: +65-6221-2529, E-mail: antonio@duke-nus.edu.sg

Received on May 30, 2017. Revised on August 15, 2017. Accepted on September 13, 2017. Published online January 11,2018

pISSN 1976-2283 eISSN 2005-1212 https://doi.org/10.5009/gnl17233

(a) This is an Open Access article distributed under the terms of the Creative Commons Attribution Non-Commercial License (http://creativecommons.org/licenses/by-nc/4.0) which permits unrestricted non-commercial use, distribution, and reproduction in any medium, provided the original work is properly cited. 
the restoration of anti-HBV immunity.

\section{WHY WE SHOULD BOOST THE HOST IMMUNE SYSTEM IN CHRONIC HBV INFECTION?}

The rational of immune based approaches to achieve functional cure of $\mathrm{HBV}$ infection stems primarily from studies that have analyzed the profile of innate and adaptive immunity during HBV infection, but also from observations derived from HBV-infected patients under immunosuppressive treatment or bone marrow transplantation. ${ }^{7,8}$

During natural HBV infection the innate immune system is poorly activated, due to an intrinsic ability of the virus to escape recognition. Readers are directed to these recent reviews for in depth description of such mechanism. ${ }^{5,9}$ Note however, that although acute and chronic HBV infections are associated with poor activation of innate immunity, HBV replication is efficiently suppressed by adequate innate immune triggering. Intracellular activation of retinoic acid-inducible gene-I (RIGI) ${ }^{10}$ or apolipoprotein B mRNA editing catalytic polypeptide-like $(\mathrm{APOBEC})^{11}$ pathways in HBV-infected hepatocytes are able to suppress HBV replication. Similarly, different cytokines such as IFN $\alpha,{ }^{12}$ IFN $\gamma$, tumor necrosis factor- $\alpha$ (TNF $\alpha$ ), and interleukin$1 \beta(\mathrm{IL}-1 \beta)^{13,14}$ produced by non-parenchymal cells of the liver can suppress, or even eradicate HBV from infected hepatocytes. The ability of innate cytokines to suppress HBV is also supported by the observation that co-infection with hepatotropic viruses able to activate innate immunity like HCV and hepatitis D virus, causes a drop of HBV replication. ${ }^{15,16}$ Thus, strategies aiming to activate these different components of innate immunity and to obtain for example a localized production of antiviral cytokines in the liver have been sought as possible immunological based therapies for HBV. ${ }^{17}$

The role of natural killer (NK) cells in HBV infection remains

Table 1. Therapeutic Strategies Aimed at Increasing Innate and Adaptive Immunity

\begin{tabular}{|c|c|c|c|}
\hline Compound & Mode of action & Stage of development & Reference \\
\hline TLR-7 agonist & $\begin{array}{l}\text { Preferential activation of intrahepatic dendritic } \\
\text { cells triggers production of type I and II } \\
\text { interferons and activation of intrahepatic NK } \\
\text { and MAIT cells }\end{array}$ & $\begin{array}{l}\text { GS9620 tested in vitro, animal } \\
\text { models (chimpanzees and } \\
\text { woodchucks; dose, } 1 \mathrm{mg} / \mathrm{kg} \text { ) } \\
\text { and CHB patients (lower dose, } \\
4 \mathrm{mg} \text { total) }\end{array}$ & $37-39$ \\
\hline TLR-8 agonist & $\begin{array}{l}\text { Preferential activation of intrahepatic dendritic } \\
\text { cells and other myeloid cells. Production of } \\
\text { IL-12/IL-18 activation of NK and MAIT cells }\end{array}$ & $\begin{array}{l}\text { In vitro and animal models } \\
\text { (woodchucks) }\end{array}$ & 40 \\
\hline RIG-I agonist & Activation of intrahepatic innate immunity & In vitro trial in human started & 36 \\
\hline TCR-like antibodies & $\begin{array}{l}\text { Direct recognition of HBV infected hepato- } \\
\text { cytes/not blocked by secreted HBeAg/HBsAg }\end{array}$ & In vitro only & 43 \\
\hline Anti-HBV antibodies & $\begin{array}{l}\text { Prevent HBV infection of hepatocytes. Pos- } \\
\text { sible recognition of HBV infected cells, lysis } \\
\text { through ADCC }\end{array}$ & $\begin{array}{l}\text { In vitro and animal models } \\
\text { (mouse models) }\end{array}$ & 25 \\
\hline $\begin{array}{l}\text { Check point inhibitors } \\
\text { (anti-PD-1) }\end{array}$ & $\begin{array}{l}\text { Restoration of function of exhausted HBV- } \\
\text { specific T cells }\end{array}$ & $\begin{array}{l}\text { In vitro, in vivo and in patients } \\
\text { (trial in anti-HBe CHB patients } \\
\text { and in patients with HCC in } \\
\text { HBV infection) }\end{array}$ & $\begin{array}{c}\text { 46,47,51,61 } \\
\text { http://www.natap.org/2017/ } \\
\text { EASL/EASL_55.htm }\end{array}$ \\
\hline $\begin{array}{l}\text { Therapeutic vaccines (different } \\
\text { preparations with arrays of } \\
\text { HBV proteins produced by } \\
\text { different vectors and } \\
\text { adjuvants) }\end{array}$ & $\begin{array}{l}\text { Induction of new HBV-specific T and B cell } \\
\text { immunity with curative ability }\end{array}$ & $\begin{array}{l}\text { Several preparations have been } \\
\text { tested in animal models and } \\
\text { humans }\end{array}$ & $52-60$ \\
\hline TCR/CAR redirected T cells & $\begin{array}{l}\text { Engineering new HBV-T cells with classical } \\
\text { TCR or with CAR }\end{array}$ & $\begin{array}{l}\text { Tested in HBV transgenic mice } \\
\text { and in patients with relapses } \\
\text { of HBV-related HCC }\end{array}$ & $69-73$ \\
\hline
\end{tabular}

TLR, Toll-like receptor; NK, natural killer; MAIT, mucosal associated invariant T; CHB, chronic hepatitis B; IL, interleukin; RIG-I, retinoic acidinducible gene-I; TCR, T cell receptor; HBV, hepatitis B virus; HBeAg, hepatitis B e antigen; HBsAg, hepatitis B surface antigen; ADCC, antibodydependent cellular cytotoxicity; PD-1, programmed cell death-1; HCC, hepatocellular carcinoma; CAR, chimeric antigen receptors. 
controversial with demonstration of a possible protective or pathogenic role. ${ }^{18}$ The ability of IFN $\alpha$ therapies to control HBV replication has been linked with activation of NK cells ${ }^{19}$ which can be also detected in patients who controlled acute HBV infection. ${ }^{20,21}$ However, at present it is not clear whether NK cells preferentially target $\mathrm{HBV}$-infected hepatocytes or have a regulatory capacity on HBV-specific T cells. ${ }^{22}$

Similarly, even though anti-HBs antibodies have protective capacity and a defective humoral response has been implicated in HBV chronicity, the quantity and functionality of HBV-specific B cell responses during HBV infection is still poorly understood. $^{23}$ The reactivation of HBV replication in a proportion of $B$ cell depleted patients treated with rituximab support a role in $\mathrm{HBV}$ control $^{24}$ and the therapeutic efficacy of anti-HBs antibody has been shown with HBV transgenic mice. ${ }^{25}$

The importance of $\mathrm{T}$ cells in establishing a functional cure of chronic HBV infection is instead a very established concept based on data obtained from patients and animal models. In chimpanzees acutely infected with HBV, deletion of CD8 T cells causes the establishment of a chronic HBV infection. ${ }^{26}$ Patients with acute HBV infection mount a cellular anti-HBV immune response that is temporally correlated with HBV serum clearance. ${ }^{27-29}$ However, HBV-specific T cells are quantitatively and functionally defective in CHB patients. ${ }^{30}$ On the other hand, immunosuppressive treatments targeting cellular immunity in anti-hepatitis B core (anti-HBc) positive subjects often trigger rapid reactivation of $\mathrm{HBV} .^{31}$ These data therefore indicate that virus specific $\mathrm{T}$ cells have the capacity to maintain HBV infection under tight replicative control.

\section{THERAPEUTIC STRATEGIES TARGETING INNATE IMMU- NITY}

Therapeutic strategies aimed at increasing innate immunity (Table 1, Fig. 1A) exploit the robust antiviral efficacy demonstrated by distinct cytokines (TNF $\alpha$, IFN $\alpha$, IFN $\gamma$ and IL$1 \beta)^{13,14,32,33}$ mimicking the activation of innate immunity during the early phase of acute HBV infection ${ }^{20}$ and inducing a potent maturation of the adaptive immunity. ${ }^{34,35}$ Toll-like receptor (TLR) or RIG-I agonists have been developed to trigger activation of

Immunotherapeutic strategies for HBV functional cure

A

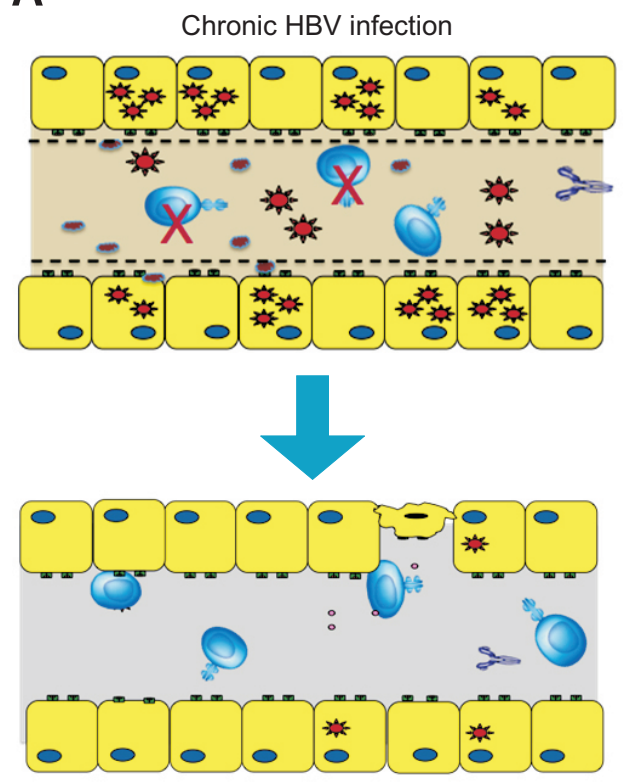

Resolved HBV

"functional cure"
B

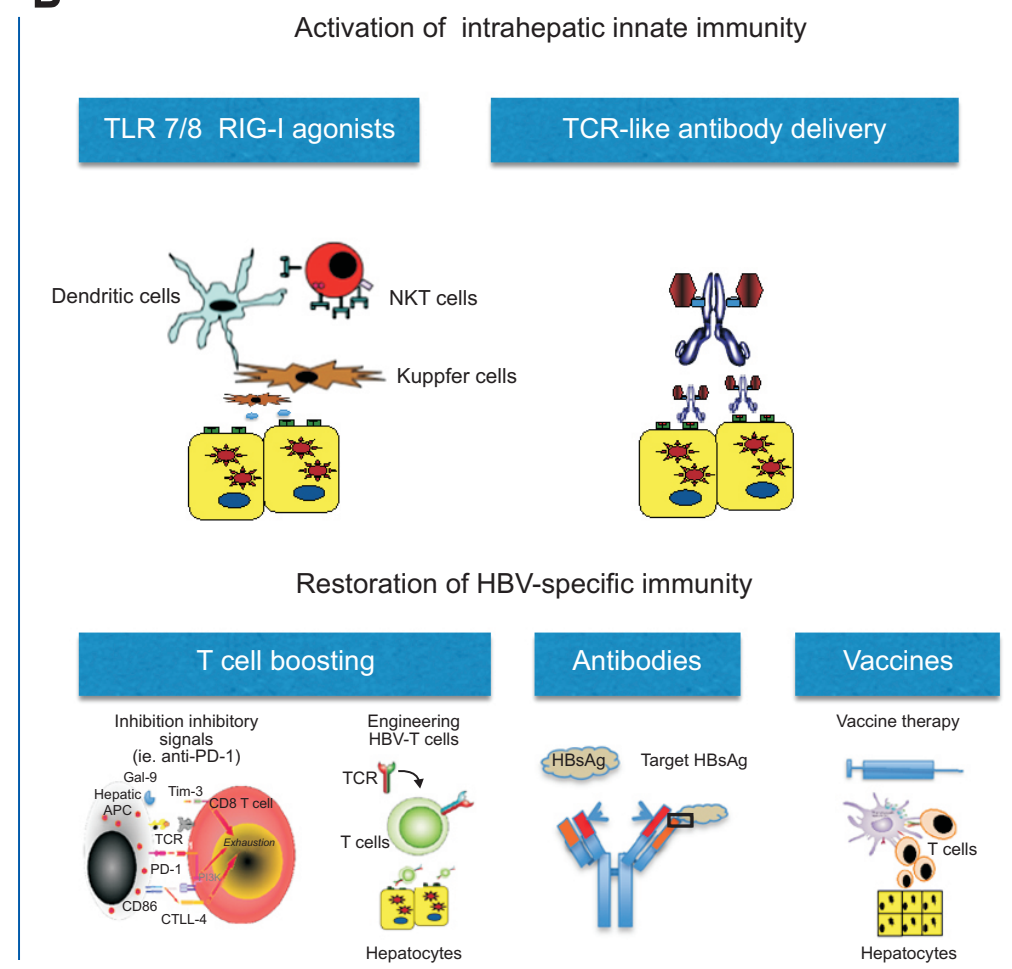

Fig. 1. Immune therapeutic approaches to achieve a functional cure of hepatitis B virus (HBV). (A) Schematic representation of immune responses and viral load in chronic and resolved HBV infection. Chronic HBV infection is characterized by the loss or functional exhaustion of HBV-specific CD8 T cells and elevated HBV load in infected hepatocytes. Resolved HBV infection is characterized by the presence of functional HBV-specific T cells, antibodies blocking new infection and few hepatocytes harboring HBV. (B) Schematic representation of different immunotherapeutic strategies able to boost innate or adaptive immunity to suppress HBV replication.

TLR, Toll-like receptor; RIG-I, retinoic acid-inducible gene-I; NKT, natural killer T; TCR, T cell receptor; APC, antigen-presenting cell; PD-1, programmed cell death-1; HBsAg, hepatitis B surface antigen. 
innate cytokines directly from hepatocytes (RIG-I) ${ }^{36}$ or from neighboring immune cells (TLR-7 and TLR-8 agonists). ${ }^{37}$ A TLR7 agonist (GS-9620) has been developed and demonstrated to induce IFN $\alpha$ production in plasmacytoid dendritic cells (pDCs). Oral administration of this compound induces a preferential activation of pDC in the gut and liver. ${ }^{37}$ The drug administered to HBV-infected chimpanzees and woodchucks infected by woodchuck hepatitis B virus (WHBV) have shown a robust even though transient anti-HBV activity. ${ }^{37,38}$

The compound has been also already tested in a phase I/ II clinical trial without side effect but scarce antiviral efficacy, likely due to the low dose used in patients (4 mg per patient compared to $1 \mathrm{mg} / \mathrm{kg}$ in chimpanzees). ${ }^{39} \mathrm{New}$ compounds with TLR-8 activity are also in development. TLR-8 agonists have been shown to be the most robust activator of pattern recognition receptors present in the intrahepatic environment. ${ }^{40}$ Such compound should trigger a more robust IFN $\gamma$ response in the liver in comparison to TLR-7 agonist thanks to its ability to activate IL-12 and IL-18 secretion from intrahepatic monocytes/ DCs. $^{40}$

These cytokines can then activate intrahepatic NK and natural killer T cells, particularly mucosal associated invariant T (MAIT) cells that constitute a large proportion of $\mathrm{T}$ cells expressing NK markers in the human liver, ${ }^{41}$ to produce large a quantity of IFN $\gamma$. In addition, IL-12 has been shown to boost the partial recovery of exhausted HBV-specific T cells ${ }^{42}$ raising the possibility that such compounds might not only directly suppress HBV replication by triggering the production of antiviral cytokines but also by boosting the intrahepatic $\mathrm{T}$ cell response.

Other strategies to augment the innate immune response within the HBV-infected liver are to selectively direct different cytokines to HBV-infected hepatocytes (Table 1, Fig. 1A). For example a $\mathrm{T}$ cell receptor (TCR)-like antibody conjugated with IFN $\alpha$ has been shown to specifically target and deliver the antiviral cytokine to HBV-infected hepatocytes. ${ }^{43}$

The approach is to produce antibodies that are specific only for HBV-infected cells thanks to their ability to recognize the HBV-peptide/human leukocyte antigen (HLA)-complexes present on the surface of infected hepatocytes. Since these antibodies do not recognize HBV conformational antigens, they are not blocked by the high quantity of HBs or HBe antigens present in the serum of CHB patients and as such, target HBV-infected hepatocytes without the interference of HBV secretory antigens. In addition, they will not target other cells, like monocytes that have internalized these HBV antigens in CHB patients. ${ }^{44}$ These antibodies have been shown to work in vitro but functional testing in animal model has not been performed yet. ${ }^{45}$ A note of caution about these strategies designed to increase intrahepatic cytokines like IFN $\alpha$ or IL-12 is that these cytokines can also directly activate NK cells. We have pointed out above that NK activation might have a dual effect. They can directly target HBVinfected hepatocytes but also act as a rheostat to HBV-specific $\mathrm{T}$ cells. The possibility that activators of innate immunity might suppress HBV-specific immunity should be therefore considered.

\section{THERAPEUTIC STRATEGIES TARGETING ADAPTIVE IMMUNITY}

The importance of specific $\mathrm{T}$ cell responses in the control of HBV replication have stimulated the development of strategies designed to enhance HBV-specific $\mathrm{T}$ cell responses in chronic HBV patients. Two strategies can be envisaged: one designed to boost the defective HBV-specific T cells still present in some chronic HBV patients, another one to engineer new HBV-specific $\mathrm{T}$ cells that can be adoptively transferred into patients (Table 1 , Fig. 2).

Therapies based on the concept of boosting HBV-specific T cells present in limited numbers in patients with chronic HBV infection are primarily represented by therapies with checkpoint inhibitors (anti-programmed cell death-1 [PD-1], anti-CTLA-4, etc.) or therapeutic vaccines. Experimental data have shown that the function of peripheral and intrahepatic exhausted HBV-
Strategies to boost HBV-specific T cells

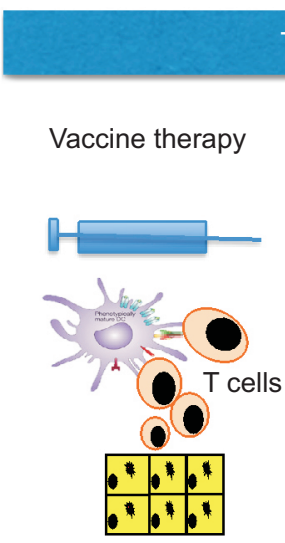

Hepatocytes

\section{T cell boosting}

$$
\begin{aligned}
& \text { Inhibition inhibitory } \\
& \text { signals }
\end{aligned}
$$

(ie. anti-PD-1)

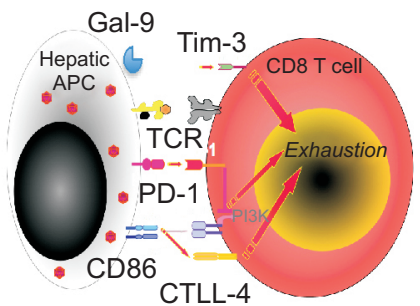

T cell engineering

\section{Engineering HBV-T cells}

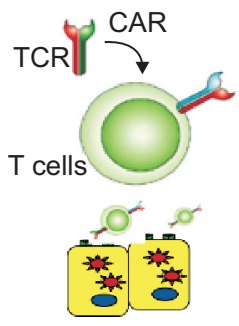

Hepatocytes
Fig. 2. Therapeutic strategies designed to restore hepatitis B virus (HBV)-specific T cell responses in chronic hepatitis B patients. Vaccine therapy aims to induce and boost new HBV-specific T cells and check point inhibitors (anti-PD-1/antiPD-L1) to restore the functionality of existing exhausted HBV-specific $\mathrm{T}$ cells. $\mathrm{T}$ cell engineering aims to produce new HBV-specific T cells through the introduction of genetic information (DNA or messenger RNA) encoding HBV-specific T cell receptors into the patients' $\mathrm{T}$ cells. APC, antigen-presenting cells; TCR, $\mathrm{T}$ cell receptor; CAR, chimeric antigen receptor. 
specific $\mathrm{T}$ cells ${ }^{46,47}$ can be partially restored in vitro by antiPD1/PDL-1 blockade. However, at the moment, therapies with checkpoint inhibitors have been used successfully only in some solid malignancies such as lung, renal cell carcinoma and melanoma, ${ }^{48,49}$ with limited data in HCC and only reports of inadequate efficacy in chronic HCV patients ${ }^{50}$ and in $\mathrm{CHB}$ patients with HCC. ${ }^{51}$ Data are starting to emerge about a restricted but present antiviral activity of anti-PD1 therapy in CHB patients (see http://www.natap.org/2017/EASL/EASL_55.htm), but selection of patients, dose of anti-PD-1 antibodies and stage of chronic $\mathrm{HBV}$ infection are variables that can influence the efficacy and need to be investigated.

Vaccine therapies have already been used in several trials in chronic HBV patients (for a complete and detailed review see $^{52,53}$ ). Attempts to increase the quantity and function of antiviral $\mathrm{T}$ cells using different HBV vaccine compositions or activation of professional antigen presenting cells naturally loaded with $\mathrm{HBV}$ antigens ${ }^{44}$ have shown some efficacy in vitro and in animal models. ${ }^{54}$ However, initial trials with the use of classical prophylactic vaccines show suboptimal and conflicting results. ${ }^{55-57}$ Moreover, attempts to use new vaccine formulations or combination therapies with antivirals have demonstrated only limited effect ${ }^{58-60}$ in patients. Currently only a small trial of therapeutic vaccination in combination with anti-PD-1 infusion has shown good efficacy in woodchucks. ${ }^{61}$ However, we need to remember that the extreme rarity of HBV-specific immune cells in chronic HBV patients, and their exhausted phenotype ${ }^{46,62-64}$ and metabolic alterations ${ }^{65,66}$ highlight the difficulty of boosting the existent HBV-specific T cells, particularly in the category of $\mathrm{CHB}$ that is more in need, hepatitis $\mathrm{B}$ e antigen positive (HBeAg+) patients with high levels of HBsAg and viral replication.

Therefore the development of strategies of immune restoration based on adoptive transfer of newly engineered HBV-specific T cells has emerged. ${ }^{67}$ Clinical evidences are supporting this strategy since treatment of patients with leukemia and chronic HBV infection with bone marrow transplant from subjects with a HBV-specific T cell response (subjects vaccinated with HBV or subjects who have spontaneously controlled HBV infection) ${ }^{7,8}$ leads to HBV clearance. Similarly, transplantation of a HBVinfected liver into a subject with HBV-specific adaptive immunity resulted in subsequent HBV clearance ${ }^{68}$ associated with an increase in HBV-specific cellular and humoral responses. Taken together, these data support the hypothesis that direct adoptive transfer of HBV-specific T cells in patients with chronic HBV infection might lead to HBV control.

For these reasons, design and expansion of differently engineered HBV-specific T cells for adoptive $\mathrm{T}$ cell transfer have been attempted. T cells able to recognize HBV-infected cells have been constructed using a chimeric antigen receptor made of an anti-HBs-specific antibody or using canonical HLA-class I restricted HBV-specific $\mathrm{T}$ cell receptors. ${ }^{6-71}$ These cells are able to recognize HBV-infected targets in vitro and data from animal models ${ }^{71}$ or selected clinical situations ${ }^{72}$ are encouraging: HBVspecific TCR redirected T cells induce a substantial reduction of HBsAg in a patient where HBsAg was produced by HCC cells with HBV-DNA integration. Furthermore, new data in humanized chimeric mice carrying HBV-infected human hepatocytes demonstrated the ability of TCR-redirected $\mathrm{T}$ cells to recognize HBV-infected hepatocytes and cause a significant drop of HBV DNA. $^{73}$

A major problem of adoptive $\mathrm{T}$ cell therapy is the practical difficulty in implementing them for clinical use. ${ }^{74}$ The production of large quantities of engineered T cells is still cumbersome, strictly regulated and necessitates a laboratory with highly skilled personnel. New technology and methods are likely to progressively overcome these practical problems, but at the moment, such therapies remain only possible in a few laboratories. $^{75}$

For these reasons, strategies that utilize antibodies with TCRlike specificities ${ }^{45}$ or soluble $\mathrm{TCR}^{76}$ able to redirect endogenous $\mathrm{T}$ cells against infected hepatocytes have also been proposed. The advantages of these approaches are that they do not require manipulation of T cells outside the patient's body. The antibodies or the soluble TCR, designed to induce specific accumulation and triggering of endogenous $\mathrm{T}$ cells in close contact to their specific targets, can be injected directly into the patients. At the moment, such strategy has been used with success in human immunodeficiency virus infections (soluble TCR) ${ }^{77}$ while TCRlike antibodies have been only used to deliver cytokine payloads directly towards HBV-infected targets. ${ }^{43}$

\section{CONTROLLING HEPATIC TOXICITY IN IMMUNE THERAPY}

The therapeutic strategies designed to boost host immunity and in particular HBV-specific $\mathrm{T}$ cells in patients with chronic $\mathrm{HBV}$ infection carry the inherent risk of inducing severe liver inflammatory events. Since the liver is an organ essential for life, such risk needs to be carefully managed.

$\mathrm{HBV}$ is a non-cytopathic virus; CD8 $\mathrm{T}$ cells are essential for viral control but in addition to lyses of HBV-infected hepatocytes, they can trigger liver inflammation. ${ }^{78,79}$ It is however difficult to predict the extent of liver damage that a specific number of HBV-specific CD8 T cells can induce. Liver inflammation is not only related to the quantity and fitness of restored HBV-specific CD8 T cells (i.e., by checkpoint inhibitors therapy) or adoptively transferred engineered HBV-specific $\mathrm{T}$ cells but also to the modification of the liver environment induced by the chronic infection. Human studies performed to quantify the number of HBV-specific CD8 $\mathrm{T}$ cells in different clinical situations have for example clearly demonstrated that a direct proportionality between HBV-specific CD8 T cells and extent of liver damage is observed only in patients with acute hepatitis. ${ }^{29}$ Such direct correlation does not exist in chronic HBV patients where liver damage is related to the ability of HBV-specific 
CD8 T cells to trigger the recruitment of inflammatory cells. ${ }^{80}$ Furthermore, it has been recently shown that similar numbers of HBV-specific T cells can be demonstrated in chronic HBV patients with active hepatitis or in those with a complete absence of liver inflammatory events. ${ }^{81,82}$ In addition, high frequencies of liver resident HBV-specific T cells were found in subjects with normal liver, showing that intrahepatic HBV-specific T cell can have pure protective ability and are not correlated with the extent of liver damage. ${ }^{83}$

The causes of why liver inflammatory patterns cannot be directly correlated with the quantity of HBV-specific T cells are not completely clear, but it is instead certain that several variables can modulate both liver inflammatory events and $\mathrm{T}$ cell fitness. For example, release of arginase directly from hepatocytes or from myeloid suppressor cells has been shown to dampen T cell function. ${ }^{84-86}$ Equally, NK cells ${ }^{18}$ or regulatory cells $^{87}$ present in the liver might inhibit $\mathrm{T}$ cell function or suppress inflammatory events while chronic liver inflammation might block the access of $\mathrm{T}$ cells to their targets by altering the normal anatomy of liver endothelial cells. On the other hand, liver inflammatory events can profoundly alter the population of intrahepatic myeloid cells. The recruitment of inflammatory monocytes might alter the normal tolerogenic environment of the liver, characterized by the presence of Kupffer cells with tolerogenic and anti-inflammatory features, ${ }^{88}$ to a more proinflammatory environment. We have recently demonstrated an enrichment of inflammatory monocytes in the intrahepatic environment of patients with advanced liver pathologies. ${ }^{89}$ These myeloid cells do not carry the classical anti-inflammatory features of resident intrahepatic monocytes (Kupffer cells), but are constantly producing inflammatory cytokines trough activation with bacterial products. ${ }^{89}$ It might be hypothesized that activation of HBV-specific CD8 $\mathrm{T}$ cells in an environment rich of such inflammatory myeloid cells will initiate a more severe inflammation of the liver. In other words, similar levels of CD8 $\mathrm{T}$ cells responses in different liver microenvironments would trigger different degrees of liver inflammation (Fig. 3). The risk of inducing severe liver damage through the use of immune therapy is therefore still difficult to predict. It can be potentially managed by a careful selection of CHB patient populations, but research efforts need to be boosted to understand which is the liver environment that can better support an exogenous activation of innate or adaptive intrahepatic immunity.

One other strategy to reduce the risk of liver toxicities is to develop approaches with lower ability to trigger inflammatory events. Indeed, if the restoration of HBV-specific T cell response in chronic HBV patients through checkpoint inhibitors or vaccines is difficult to modify or predict and would be related to the quantity of exhausted $\mathrm{T}$ cells present in the distinct groups of patients, adoptive $\mathrm{T}$ cell transfer can be performed with engineered HBV-specific CD8 $\mathrm{T}$ cells with reduced ability to trigger inflammatory events. One of these strategies is based on the uti- lization of T cells engineered to only transiently express HBVspecific TCRs through non-viral gene transfer systems. T cells transduced by viral vectors stably express the TCRs, and their unchecked expansion might lead to progressive liver toxicities that is difficult to manage clinically. To bypass this problem, we implemented a strategy where $\mathrm{T}$ cells are engineered through messenger RNA (mRNA) electroporation and they express HBVspecific TCRs for only 3 to 5 days. $^{90}$ In addition, to circumvent safety concerns related to stable genetic manipulation of $\mathrm{T}$ cells induced by viral vectors, these cells with limited life-span can be adoptively transferred in escalating doses and their potential toxicities are more easily managed than stably transduced TCRredirected T cells. Despite their transient expression of TCRs, mRNA TCR-redirected T cells control the expansion of HBVexpressing hepatoma cells in mice. ${ }^{90}$ Furthermore, the antiviral activity of mRNA TCR-redirected T cells was also recently tested in an HBV-infected human liver chimeric uPA/SCID/IL $\gamma$ R2 (USG) mouse model. ${ }^{73}$ These mRNA TCR-redirected T cells were shown to preferentially home to the liver of HBV-infected mice and induced a progressive but timely controlled virus-specific immune-mediated reduction of serological and intrahepatic HBV viral loads ( $\sim 1$ to 1.5 log reduction of HBV DNA after 3 doses of 0.5 million T cells).

Importantly, mRNA TCR-redirected $\mathrm{T}$ cells trigger only a temporary immune-mediated killing of the infected hepato-

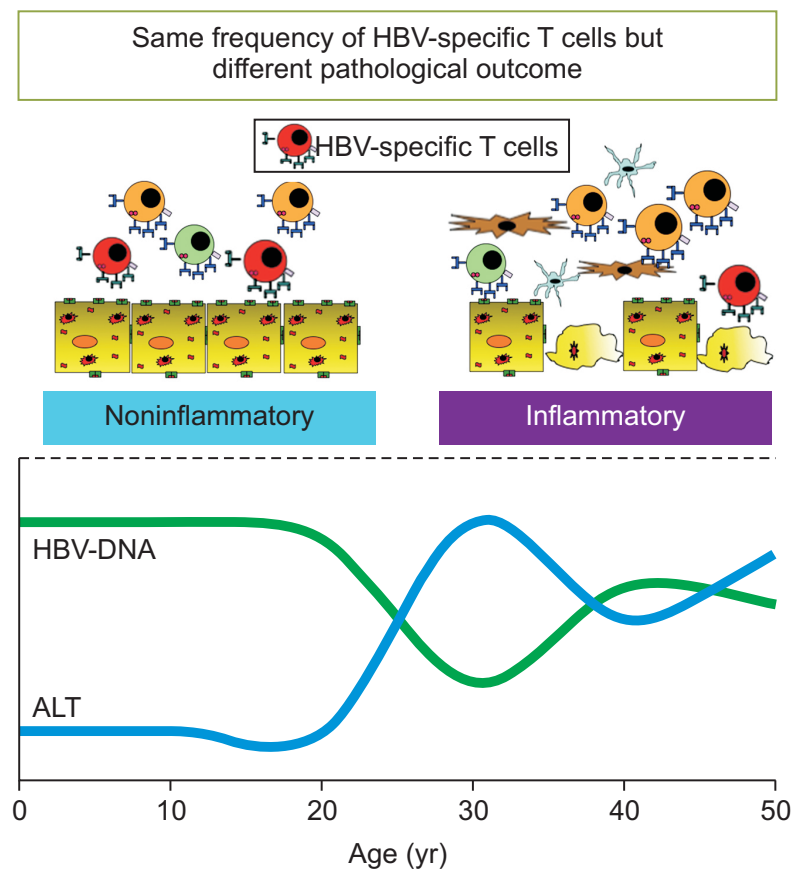

Fig. 3. Pathogenesis of liver damage during chronic hepatitis B virus (HBV) infection. Increased levels of alanine aminotransferase (ALT) are not proportional to the quantity of HBV-specific CD8 T cells. Liver damage is mediated by the intrahepatic recruitment of inflammatory cells. Similar frequencies of HBV-specific CD8 T cells can trigger different inflammatory outcomes depending on the changes in the liver microenvironment. 
cytes. Ten days after infusion the treated mice show a reversion of transaminase levels identical to the ones detected prior to therapy. Such data are important for the clinical translation of $\mathrm{T}$ cell therapy into patients, since the temporary effect of mRNA TCR-redirected T cells will permit a safe implementation of dose escalating regimes. This could allow the optimization of dose and therapy length required to achieve substantial reduction of HBV-infected hepatocytes without triggering severe inflammatory events that should subside when the expression of HBVspecific TCRs disappear from the adoptively transferred $\mathrm{T}$ cells. The flexibility of such cell preparation will also allow to study possible combination therapy with drugs suppressing HBV replication (NAs) or blocking hepatocyte re-infection and intrahepatic spreading of HBV (Myrcludex-B). ${ }^{91}$

\section{HBV IMMUNOTHERAPY - WHICH PATIENTS SHOULD BE TREATED?}

Current guidelines for hepatitis B indicate that antiviral therapy should be reserved until the appearance of clinically active liver disease or the development of fibrosis. The rationale of such an approach is based on three main suppositions: (1) the initial stage of CHB infection defined as "immune tolerant" (now defined as HBeAg+ chronic infection) is a fully benign without any relevant pathological consequences; (2) only CHB patients that have active inflammation are eligible for therapy; and (3) the elevation in transaminase levels is a sign of an "awakening" of the host immune response. Although the premise on which these points are based on are not completely incorrect, we can now better define their clinical and immunological significance based on new recent data.

The first point to consider is whether the initial phase of disease is really devoid of pathological consequences and if we should wait to treat patients with chronic HBV infection until active liver inflammation occurs. We have recently demonstrated that patients in the early stages of infection exhibit already high levels of HBV DNA integration and clonal hepatocyte expansion, which may be a risk factor for $\mathrm{HCC}^{82}$ Studies have also shown that the incidence of HCC and cirrhosis is seen to increase with elevated levels of HBV DNA; moreover HBV DNA level, irrespective of biochemical activity, is a strong predictor of HCC. ${ }^{92}$ These data, therefore provide weight to the argument for earlier treatment of patients with chronic $\mathrm{HBV}^{93}$ in order to treat not only the liver inflammation but also for the prevention of liver cancer.

The second consideration is that ALT levels are not a surrogate measure of the virus-specific $\mathrm{T}$ cell response. In adenovirus infected mice, $\mathrm{T}$ cell immunity against hepatocytes was detected without an elevation of transaminase levels. ${ }^{94}$ In CHB patients, the quantity of circulating and intrahepatic HBV-specific T cells is not proportional to the level of biochemical activity. ${ }^{80,95}$ In addition, young CHB patients considered "immune tolerant" (low ALT and very high levels of HBV DNA) have a repertoire and function of HBV-specific T cells that is similar to the one of patients with chronic active hepatitis (high ALT levels and high HBV DNA). ${ }^{81}$ Thus the difference between chronic HBV patients with either low or high levels of ALT is their level of intrahepatic inflammatory cells (inflammatory monocytes, non HBVspecific T cells, NK cells) and not their level of HBV-specific immunity. Patients with a higher level of ALT might be more prone to developing an inflammatory response. Importantly, basic immunological studies comparing immune profiles of humans at different ages have shown that pro-inflammatory responses increase proportionally with age. ${ }^{96}$ As such it might be true that older patients with chronic active hepatitis have a more "awakened" host immune response, but such an "increased" immune response is certainly not HBV-specific, but it is the result of a more general trend to start and maintain an intrahepatic inflammatory reaction which increases with age. ${ }^{97}$

Therefore, we would argue that the new immunological therapies designed to boost innate or adaptive immunity in patients with chronic HBV infection (Fig. 1), might be better suited for treating young patients in the so called "immune tolerant" phase of the disease, now redefined as HBeAg+ infection, than older subjects with chronic active hepatitis B (now better defined as HBeAg+ hepatitis, EASL guidelines ${ }^{98}$ ) (Fig. 3). Our argument centers around the point that, in immunological terms, younger subjects have less compromised HBV-specific T cell function and a lower "pro-inflammatory response" than older subjects and for this reason they might be more likely to recover their HBV-specific T cell immunity and less likely develop a severe inflammatory reaction in the liver (see also ${ }^{97}$ ).

Another important consideration is that, as we have already pointed out, the presence of an inflammatory infiltrate may in fact lead to the inhibition of the HBV-specific responses that immunological therapies would like to boost. TNF $\alpha$, released by inflammatory monocytes that are increased in the advanced phase of chronic hepatitis $\mathrm{B},{ }^{89}$ can directly inhibit virus-specific T cells. ${ }^{99}$ Furthermore, the intrahepatic environment of patients with chronic active hepatitis is not conducive for antigenspecific immune function. It is enriched with regulatory immune cells (T-regs, myeloid derived suppressor cells, NK cells) that can suppress not only the inflammatory response but also HBV-specific T cells. In addition, arginase, the enzyme released by dying hepatocytes, deprive the liver environment of arginine, an essential amino acid for virus-specific T cell function. ${ }^{84-86} \mathrm{In}$ this regard, treating patients with lower levels of inflammation (or indeed lower ALT) may achieve a more beneficial outcome. In keeping with this, a small study by Gotto et al. ${ }^{100}$ showed that treatment with steroids, as a means of immunosuppression, to dampen the inflammatory infiltrate prior to NA initiation, in fact resulted in an increase of HBV-specific T cells. Furthermore, it is interesting to note that successful vaccine therapies in woodchucks with persistent WHBV infection were seen in 
animals with low or absent liver inflammatory events. ${ }^{54}$ In this context, it should also be noted that the addition of NA therapy, to decrease not only HBV DNA levels but also intrahepatic inflammatory events, might be beneficial.

Therefore, taking these data into account, it is likely that even at a similar elevated level of HBV DNA, patients with lower ALT levels, and/or of younger age may respond better to immunological based treatment. As these patients, considered immune tolerant, are usually excluded from the treatment pool, there is a paucity of data on the outcome of traditional treatment in this cohort. However, even with the few studies performed, data actually show that such patients are not at all less likely to respond to treatment. A study by Carey et al. ${ }^{101}$ showed for example that "immune tolerant" children treated with a combination of NA (Lamivudine) and Peg-IFN $\alpha$ demonstrated evidence of HBsAg loss associated with increased HBV-specific T cell proliferation early during therapy.

\section{CONCLUSIONS}

New immune therapies, currently in the pipeline, are supported by strong scientific rational but their efficacy in the real life setting remains to be seen. The risk of inducing severe liver inflammation has so far restricted direct clinical testing. We argued here that new methods of $\mathrm{T}$ cell engineering and criteria of CHB patient selection for immunotherapy should be revised, and such options can open new and safer avenues to test these new immunotherapeutic approaches.

\section{CONFLICTS OF INTEREST}

Antonio Bertoletti $(\mathrm{AB})$ declares the following relationship with commercial entities developing therapeutics for HBV treatment. He collaborates and receives research support from Gilead Sciences to test the effect of HBV antigens on immune cell function. He acted as a consultant and served on the advisory boards of Gilead Sciences, MedImmune, Jansseen-Cilag, IONIS, Abivax, HUMABS BioMed. AB is also a co-founder of LION TCR pte. ltd. a biotech company developing $\mathrm{T}$ cell receptors for treatment of virus-related cancers and chronic viral diseases.

\section{REFERENCES}

1. Stanaway JD, Flaxman AD, Naghavi M, et al. The global burden of viral hepatitis from 1990 to 2013: findings from the Global Burden of Disease Study 2013. Lancet 2016;388:1081-1088.

2. Foster GR, Afdhal N, Roberts SK, et al. Sofosbuvir and velpatasvir for HCV genotype 2 and 3 infection. N Engl J Med 2015;373:2608-2617.

3. Gish RG, Given BD, Lai CL, et al. Chronic hepatitis B: virology, natural history, current management and a glimpse at future opportunities. Antiviral Res 2015;121:47-58.
4. Block TM, Gish R, Guo H, et al. Chronic hepatitis B: what should be the goal for new therapies? Antiviral Res 2013;98:27-34.

5. Zoulim F, Lebossé F, Levrero M. Current treatments for chronic hepatitis B virus infections. Curr Opin Virol 2016;18:109-116.

6. Gill US, Zissimopoulos A, Al-Shamma S, et al. Assessment of bone mineral density in tenofovir-treated patients with chronic hepatitis B: can the fracture risk assessment tool identify those at greatest risk? J Infect Dis 2015;211:374-382.

7. Ilan Y, Nagler A, Adler R, et al. Adoptive transfer of immunity to hepatitis B virus after T cell-depleted allogeneic bone marrow transplantation. Hepatology 1993;18:246-252.

8. Lau GK, Lok AS, Liang RH, et al. Clearance of hepatitis B surface antigen after bone marrow transplantation: role of adoptive immunity transfer. Hepatology 1997;25:1497-1501.

9. Maini MK, Gehring AJ. The role of innate immunity in the immunopathology and treatment of HBV infection. J Hepatol 2016;64(1 Suppl):S60-S70.

10. Sato S, Li K, Kameyama T, et al. The RNA sensor RIG-I dually functions as an innate sensor and direct antiviral factor for hepatitis B virus. Immunity 2015;42:123-132.

11. Lucifora J, Xia Y, Reisinger F, et al. Specific and nonhepatotoxic degradation of nuclear hepatitis B virus cccDNA. Science 2014;343:1221-1228.

12. Belloni L, Allweiss L, Guerrieri F, et al. IFN-alpha inhibits HBV transcription and replication in cell culture and in humanized mice by targeting the epigenetic regulation of the nuclear cccDNA minichromosome. J Clin Invest 2012;122:529-537.

13. McClary H, Koch R, Chisari FV, Guidotti LG. Relative sensitivity of hepatitis B virus and other hepatotropic viruses to the antiviral effects of cytokines. J Virol 2000;74:2255-2264.

14. Watashi $\mathrm{K}$, Liang $\mathrm{G}$, Iwamoto $\mathrm{M}$, et al. Interleukin-1 and tumor necrosis factor-alpha trigger restriction of hepatitis B virus infection via a cytidine deaminase activation-induced cytidine deaminase (AID). J Biol Chem 2013;288:31715-31727.

15. Liaw YF, Chen YC, Sheen IS, Chien RN, Yeh CT, Chu CM. Impact of acute hepatitis $\mathrm{C}$ virus superinfection in patients with chronic hepatitis B virus infection. Gastroenterology 2004;126:10241029.

16. Sagnelli E, Coppola N, Messina V, et al. HBV superinfection in hepatitis $\mathrm{C}$ virus chronic carriers, viral interaction, and clinical course. Hepatology 2002;36:1285-1291.

17. Bertoletti A, Rivino L. Hepatitis B: future curative strategies. Curr Opin Infect Dis 2014;27:528-534.

18. Maini MK, Peppa D. NK cells: a double-edged sword in chronic hepatitis B virus infection. Front Immunol 2013;4:57.

19. Thimme R, Dandri M. Dissecting the divergent effects of interferon-alpha on immune cells: time to rethink combination therapy in chronic hepatitis B? J Hepatol 2013;58:205-209.

20. Fisicaro P, Valdatta C, Boni C, et al. Early kinetics of innate and adaptive immune responses during hepatitis B virus infection. Gut 2009;58:974-982.

21. Webster GJ, Reignat S, Maini MK, et al. Incubation phase of acute 
hepatitis B in man: dynamic of cellular immune mechanisms. Hepatology 2000;32:1117-1124.

22. Peppa D, Gill US, Reynolds G, et al. Up-regulation of a death receptor renders antiviral T cells susceptible to NK cell-mediated deletion. J Exp Med 2013;210:99-114.

23. Oliviero B, Cerino A, Varchetta S, et al. Enhanced B-cell differentiation and reduced proliferative capacity in chronic hepatitis $\mathrm{C}$ and chronic hepatitis B virus infections. J Hepatol 2011;55:53-60.

24. Yeo W, Chan TC, Leung NW, et al. Hepatitis B virus reactivation in lymphoma patients with prior resolved hepatitis B undergoing anticancer therapy with or without rituximab. J Clin Oncol 2009;27:605-611.

25. Zhang TY, Yuan Q, Zhao JH, et al. Prolonged suppression of HBV in mice by a novel antibody that targets a unique epitope on hepatitis B surface antigen. Gut 2016;65:658-671.

26. Thimme R, Wieland S, Steiger C, et al. CD8(+) T cells mediate viral clearance and disease pathogenesis during acute hepatitis $\mathrm{B}$ virus infection. J Virol 2003;77:68-76.

27. Ferrari C, Penna A, Bertoletti A, et al. Cellular immune response to hepatitis B virus-encoded antigens in acute and chronic hepatitis B virus infection. J Immunol 1990;145:3442-3449.

28. Penna A, Chisari FV, Bertoletti A, et al. Cytotoxic T lymphocytes recognize an HLA-A2-restricted epitope within the hepatitis $B$ virus nucleocapsid antigen. J Exp Med 1991;174:1565-1570.

29. Maini MK, Boni C, Ogg GS, et al. Direct ex vivo analysis of hepatitis B virus-specific CD8(+) T cells associated with the control of infection. Gastroenterology 1999;117:1386-1396.

30. Bertoletti A, Ferrari C. Adaptive immunity in HBV infection. J Hepatol 2016;64(1 Suppl):S71-S83.

31. Shouval D, Shibolet O. Immunosuppression and HBV reactivation. Semin Liver Dis 2013;33:167-177.

32. Wieland SF, Guidotti LG, Chisari FV. Intrahepatic induction of alpha/beta interferon eliminates viral RNA-containing capsids in hepatitis B virus transgenic mice. J Virol 2000;74:4165-4173.

33. Puro R, Schneider RJ. Tumor necrosis factor activates a conserved innate antiviral response to hepatitis B virus that destabilizes nucleocapsids and reduces nuclear viral DNA. J Virol 2007;81:73517362.

34. Bertoletti A, Gehring AJ. Immune therapeutic strategies in chronic hepatitis B virus infection: virus or inflammation control? PLoS Pathog 2013;9:e1003784.

35. Zoulim F, Luangsay S, Durantel D. Targeting innate immunity: a new step in the development of combination therapy for chronic hepatitis B. Gastroenterology 2013;144:1342-1344.

36. Guo F, Han Y, Zhao X, et al. STING agonists induce an innate antiviral immune response against hepatitis $B$ virus. Antimicrob Agents Chemother 2015;59:1273-1281.

37. Lanford RE, Guerra B, Chavez D, et al. GS-9620, an oral agonist of Toll-like receptor-7, induces prolonged suppression of hepatitis B virus in chronically infected chimpanzees. Gastroenterology 2013;144:1508-1517.

38. Menne S, Tumas DB, Liu KH, et al. Sustained efficacy and se- roconversion with the Toll-like receptor 7 agonist GS-9620 in the woodchuck model of chronic hepatitis B. J Hepatol 2015;62:1237-1245.

39. Gane EJ, Lim YS, Gordon SC, et al. The oral toll-like receptor-7 agonist GS-9620 in patients with chronic hepatitis B virus infection. J Hepatol 2015;63:320-328.

40. Jo J, Tan AT, Ussher JE, et al. Toll-like receptor 8 agonist and bacteria trigger potent activation of innate immune cells in human liver. PLoS Pathog 2014;10:e1004210.

41. Tang XZ, Jo J, Tan AT, et al. IL-7 licenses activation of human liver intrasinusoidal mucosal-associated invariant T cells. J Immunol 2013;190:3142-3152.

42. Schurich A, Pallett LJ, Lubowiecki M, et al. The third signal cytokine IL-12 rescues the anti-viral function of exhausted HBVspecific CD8 T cells. PLoS Pathog 2013;9:e1003208.

43. Ji C, Sastry KS, Tiefenthaler G, et al. Targeted delivery of interferon-alpha to hepatitis B virus-infected cells using T-cell receptorlike antibodies. Hepatology 2012;56:2027-2038.

44. Gehring AJ, Haniffa M, Kennedy PT, et al. Mobilizing monocytes to cross-present circulating viral antigen in chronic infection. J Clin Invest 2013;123:3766-3776.

45. Sastry KS, Too CT, Kaur K, et al. Targeting hepatitis B virusinfected cells with a T-cell receptor-like antibody. J Virol 2011;85:1935-1942.

46. Boni C, Fisicaro P, Valdatta C, et al. Characterization of hepatitis $B$ virus (HBV)-specific T-cell dysfunction in chronic HBV infection. J Virol 2007;81:4215-4225.

47. Fisicaro P, Valdatta C, Massari M, et al. Antiviral intrahepatic Tcell responses can be restored by blocking programmed death-1 pathway in chronic hepatitis B. Gastroenterology 2010;138:682693.

48. Daud AI, Loo K, Pauli ML, et al. Tumor immune profiling predicts response to anti-PD-1 therapy in human melanoma. J Clin Invest 2016;126:3447-3452.

49. Le DT, Uram JN, Wang H, et al. PD-1 blockade in tumors with mismatch-repair deficiency. N Engl J Med 2015;372:2509-2520.

50. Fuller MJ, Callendret B, Zhu B, et al. Immunotherapy of chronic hepatitis $C$ virus infection with antibodies against programmed cell death-1 (PD-1). Proc Natl Acad Sci U S A 2013;110:1500115006.

51. El-Khoueiry AB, Sangro B, Yau T, et al. Nivolumab in patients with advanced hepatocellular carcinoma (CheckMate 040): an open-label, non-comparative, phase 1/2 dose escalation and expansion trial. Lancet 2017;389:2492-2502.

52. Michel ML, Deng Q, Mancini-Bourgine M. Therapeutic vaccines and immune-based therapies for the treatment of chronic hepatitis B: perspectives and challenges. J Hepatol 2011;54:1286-1296.

53. Liu J, Kosinska A, Lu M, Roggendorf M. New therapeutic vaccination strategies for the treatment of chronic hepatitis B. Virol Sin 2014;29:10-16.

54. Kosinska AD, Zhang E, Johrden L, et al. Combination of DNA prime: adenovirus boost immunization with entecavir elicits 
sustained control of chronic hepatitis B in the woodchuck model. PLoS Pathog 2013;9:e1003391.

55. Michel ML, Pol S, Brechot C, Tiollais P. Immunotherapy of chronic hepatitis B by anti HBV vaccine: from present to future. Vaccine 2001;19:2395-2399.

56. Mancini-Bourgine M, Fontaine H, Scott-Algara D, Pol S, Bréchot C, Michel ML. Induction or expansion of T-cell responses by a hepatitis B DNA vaccine administered to chronic HBV carriers. Hepatology 2004;40:874-882.

57. Vandepapelière P, Lau GK, Leroux-Roels G, et al. Therapeutic vaccination of chronic hepatitis B patients with virus suppression by antiviral therapy: a randomized, controlled study of co-administration of $\mathrm{HBsAg} / \mathrm{ASO} 2$ candidate vaccine and lamivudine. Vaccine 2007;25:8585-8597.

58. Xu DZ, Wang XY, Shen XL, et al. Results of a phase III clinical trial with an HBsAg-HBIG immunogenic complex therapeutic vaccine for chronic hepatitis B patients: experiences and findings. J Hepatol 2013;59:450-456.

59. Godon O, Fontaine H, Kahi S, et al. Immunological and antiviral responses after therapeutic DNA immunization in chronic hepatitis B patients efficiently treated by analogues. Mol Ther 2014;22:675-684.

60. Lok AS, Pan CQ, Han SH, et al. Randomized phase II study of GS4774 as a therapeutic vaccine in virally suppressed patients with chronic hepatitis B. J Hepatol 2016;65:509-516.

61. Liu J, Zhang E, Ma Z, et al. Enhancing virus-specific immunity in vivo by combining therapeutic vaccination and PDL1 blockade in chronic hepadnaviral infection. PLoS Pathog 2014;10:e1003856.

62. Wu W, Shi Y, Li S, et al. Blockade of Tim-3 signaling restores the virus-specific $\mathrm{CD}^{+} \mathrm{T}$-cell response in patients with chronic hepatitis B. Eur J Immunol 2012;42:1180-1191.

63. Kurktschiev PD, Raziorrouh B, Schraut W, et al. Dysfunctional CD8+ $\mathrm{T}$ cells in hepatitis B and C are characterized by a lack of antigen-specific T-bet induction. J Exp Med 2014;211:20472059.

64. Bengsch B, Martin B, Thimme R. Restoration of HBV-specific CD8+ T cell function by PD-1 blockade in inactive carrier patients is linked to T cell differentiation. J Hepatol 2014;61:12121219.

65. Schurich A, Pallett LJ, Jajbhay D, et al. Distinct metabolic requirements of exhausted and functional virus-specific CD8 T cells in the same host. Cell Rep 2016;16:1243-1252.

66. Fisicaro P, Barili V, Montanini B, et al. Targeting mitochondrial dysfunction can restore antiviral activity of exhausted HBVspecific CD8 T cells in chronic hepatitis B. Nat Med 2017;23:327336.

67. Koh S, Bertoletti A. Circumventing failed antiviral immunity in chronic hepatitis B virus infection: triggering virus-specific or innate-like T cell response? Med Microbiol Immunol 2015;204:8794.

68. Loggi E, Bihl F, Chisholm JV 3rd, et al. Anti-HBs re-seroconver- sion after liver transplantation in a patient with past HBV infection receiving a HBsAg positive graft. J Hepatol 2009;50:625630.

69. Bohne F, Chmielewski M, Ebert G, et al. T cells redirected against hepatitis B virus surface proteins eliminate infected hepatocytes. Gastroenterology 2008;134:239-247.

70. Gehring AJ, Xue SA, Ho ZZ, et al. Engineering virus-specific T cells that target HBV infected hepatocytes and hepatocellular carcinoma cell lines. J Hepatol 2011;55:103-110.

71. Krebs K, Böttinger N, Huang LR, et al. T cells expressing a chimeric antigen receptor that binds hepatitis B virus envelope proteins control virus replication in mice. Gastroenterology 2013;145:456465.

72. Qasim W, Brunetto M, Gehring AJ, et al. Immunotherapy of HCC metastases with autologous $\mathrm{T}$ cell receptor redirected T cells, targeting HBsAg in a liver transplant patient. J Hepatol 2015;62:486-491.

73. Kah J, Koh S, Volz T, et al. Lymphocytes transiently expressing virus-specific T cell receptors reduce hepatitis B virus infection. J Clin Invest 2017;127:3177-3188.

74. June CH, Blazar BR, Riley JL. Engineering lymphocyte subsets: tools, trials and tribulations. Nat Rev Immunol 2009;9:704-716.

75. Kaiser AD, Assenmacher M, Schröder B, et al. Towards a commercial process for the manufacture of genetically modified $\mathrm{T}$ cells for therapy. Cancer Gene Ther 2015;22:72-78.

76. Oates J, Hassan NJ, Jakobsen BK. ImmTACs for targeted cancer therapy: why, what, how, and which. Mol Immunol 2015;67(2 Pt A):67-74.

77. Yang H, Buisson S, Bossi G, et al. Elimination of latently HIVinfected cells from antiretroviral therapy-suppressed subjects by engineered immune-mobilizing T-cell receptors. Mol Ther 2016;24:1913-1925.

78. Sitia G, Isogawa M, Iannacone M, Campbell IL, Chisari FV, Guidotti LG. MMPs are required for recruitment of antigennonspecific mononuclear cells into the liver by CTLs. J Clin Invest 2004;113:1158-1167.

79. Ando K, Moriyama T, Guidotti LG, et al. Mechanisms of class I restricted immunopathology: a transgenic mouse model of fulminant hepatitis. J Exp Med 1993;178:1541-1554.

80. Maini MK, Boni C, Lee CK, et al. The role of virus-specific CD8(+) cells in liver damage and viral control during persistent hepatitis B virus infection. J Exp Med 2000;191:1269-1280.

81. Kennedy PT, Sandalova E, Jo J, et al. Preserved T-cell function in children and young adults with immune-tolerant chronic hepatitis B. Gastroenterology 2012;143:637-645.

82. Mason WS, Gill US, Litwin S, et al. HBV DNA integration and clonal hepatocyte expansion in chronic hepatitis B patients considered immune tolerant. Gastroenterology 2016;151:986-998.

83. Pallett LJ, Davies J, Colbeck EJ, et al. IL-2(high) tissue-resident T cells in the human liver: Sentinels for hepatotropic infection. $\mathrm{J}$ Exp Med 2017;214:1567-1580.

84. Pallett LJ, Gill US, Quaglia A, et al. Metabolic regulation of hepa- 
titis B immunopathology by myeloid-derived suppressor cells. Nat Med 2015;21:591-600.

85. Sandalova E, Laccabue D, Boni C, et al. Increased levels of arginase in patients with acute hepatitis B suppress antiviral T cells. Gastroenterology 2012;143:78-87.

86. Das A, Hoare M, Davies N, et al. Functional skewing of the global CD8 $\mathrm{T}$ cell population in chronic hepatitis B virus infection. J Exp Med 2008;205:2111-2124.

87. Xu D, Fu J, Jin L, et al. Circulating and liver resident CD4+CD25+ regulatory $\mathrm{T}$ cells actively influence the antiviral immune response and disease progression in patients with hepatitis B. J Immunol 2006;177:739-747.

88. Sitia G, Iannacone M, Aiolfi R, et al. Kupffer cells hasten resolution of liver immunopathology in mouse models of viral hepatitis. PLoS Pathog 2011;7:e1002061.

89. Tan-Garcia A, Wai LE, Zheng D, et al. Intrahepatic CD206(+) macrophages contribute to inflammation in advanced viralrelated liver disease. J Hepatol 2017;67:490-500.

90. Koh S, Shimasaki N, Suwanarusk R, et al. A practical approach to immunotherapy of hepatocellular carcinoma using $\mathrm{T}$ cells redirected against hepatitis B virus. Mol Ther Nucleic Acids 2013;2:e114.

91. Petersen J, Dandri M, Mier W, et al. Prevention of hepatitis B virus infection in vivo by entry inhibitors derived from the large envelope protein. Nat Biotechnol 2008;26:335-341.

92. Chen CJ, Yang HI, Su J, et al. Risk of hepatocellular carcinoma across a biological gradient of serum hepatitis B virus DNA level. JAMA 2006;295:65-73.

93. Zoulim F, Mason WS. Reasons to consider earlier treatment of chronic HBV infections. Gut 2012;61:333-336.

94. Stabenow D, Frings M, Trück C, et al. Bioluminescence imaging allows measuring CD8 T cell function in the liver. Hepatology 2010;51:1430-1437.

95. Webster GJ, Reignat S, Brown D, et al. Longitudinal analysis of CD8+ T cells specific for structural and nonstructural hepatitis B virus proteins in patients with chronic hepatitis B: implications for immunotherapy. J Virol 2004;78:5707-5719.

96. Kollmann TR, Levy 0, Montgomery RR, Goriely S. Innate immune function by Toll-like receptors: distinct responses in newborns and the elderly. Immunity 2012;37:771-783.

97. Bertoletti A, Kennedy PT. The immune tolerant phase of chronic HBV infection: new perspectives on an old concept. Cell Mol Immunol 2015;12:258-263.

98. European Association for the Study of the Liver. EASL 2017 clinical practice guidelines on the management of hepatitis B virus infection. J Hepatol 2017;67:370-398.

99. Beyer M, Abdullah Z, Chemnitz JM, et al. Tumor-necrosis factor impairs CD4(+) T cell-mediated immunological control in chronic viral infection. Nat Immunol 2016;17:593-603.

100. Gotto J, Webster GJ, Brown D, Jenkins J, Dusheiko GM, Bertoletti A. The impact of HBV-DNA fluctuations on virus-specific CD8+ T cells in $\mathrm{HBeAg}+$ chronic hepatitis B patients treated with a steroid and lamivudine. J Viral Hepat 2006;13:415-425.

101. Carey I, D’Antiga L, Bansal S, et al. Immune and viral profile from tolerance to hepatitis B surface antigen clearance: a longitudinal study of vertically hepatitis B virus-infected children on combined therapy. J Virol 2011;85:2416-2428. 